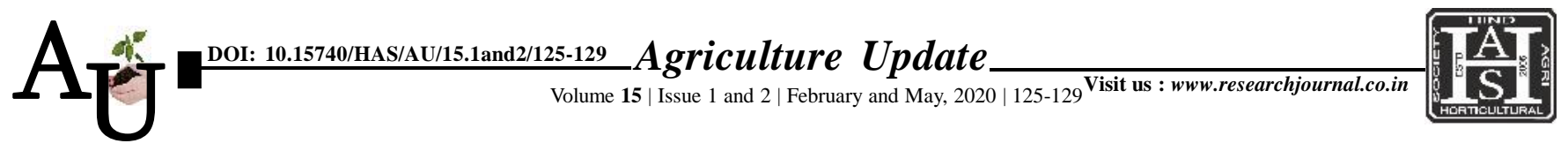

- ISSN-0973-1520

\title{
A Cass Stup: $\quad$ Use of CeRA consortium by research scholars of University of Agricultural Sciences in Karnataka
}

\author{
Ekanath Rathod, Krishna S. Maraddi and Kumaraswamy Hiremath
}

Article Chronicle:

SUMMARY : Information communication technology (ICT) has given many e-services to the libraries Received : in the present era. Libraries are using ICT to improve the management of scholarly information to 31.03.2020;

Accepted : strengthen and speedy access to such information not available locally. Consortium for e-Resources in Agriculture (CeRA) is most valuable research tool that, instead of print based services in traditional 28.04.2020

KEY WoRDS: library services. In this study an attempt has been made to search use of CeRA consortium by research scholars in University of Agricultural Sciences, Dharwad. It included use and access of CeRA, frequency and purpose of using CeRA. Also Escalating of CeRA services by adding more resources and facilities has given strong information support for the teaching, research and extension programmers.

How to cite this article : Rathod, Ekanath, Maraddi, Krishna S. and Hiremath, Kumaraswamy (2020). Use of CeRA consortium by research scholars of University of Agricultural Sciences in Karnataka. Agric. Update, 15(1 and 2): 125-129; DOI : 10.15740/HAS/AU/15.1and2/125-129. Copyright@ 2020: Hind Agri-Horticultural CeRA, Agriculture, Consortium, e-Resource, e-Service 